Bond University ePublications@bond

Sports Law eJournal

Faculty of Law

6-26-2013

\title{
Development through sport: Fans and critics
}

Danielle Ireland-Piper

Bond University, Danielle_Ireland_Piper@bond.edu.au

Follow this and additional works at: http://epublications.bond.edu.au/slej

Part of the Entertainment, Arts, and Sports Law Commons

\section{Recommended Citation}

Danielle Ireland-Piper. (2013) "Development through sport: Fans and critics" , : ISSN 1836-1129.

http://epublications.bond.edu.au/slej/17

This Journal Article is brought to you by the Faculty of Law at ePublications@bond. It has been accepted for inclusion in Sports Law eJournal by an authorized administrator of ePublications@bond. For more information, please contact Bond University's Repository Coordinator. 


\title{
Development through sport: Fans and critics
}

\begin{abstract}
Sport is used as a tool for development, dispute resolution and reconciliation. The use of sport to meet development goals such as education, health and gender equity has grown into a widely recognised form of development assistance, commonly known as 'Development through Sport' (DTS). Further, the right to physical activity is a substantive human right. Nonetheless, the DTS movement has both its fans and critics. This article analyses four common concerns; namely, that DTS is racially constructed, lacking in credibility, poorly coordinated and inadequately evaluated. This article agrees that the DTS movement should improve the delivery and implementation of development goals, but suggests that the criticisms are overstated. They are far outweighed by the benefits of DTS, which meet a number of the United Nations Millennium Development Goals.
\end{abstract}

\section{Keywords}

sport, Development Through Sport, DTS, dispute resolution, education, health, gender, equity

\section{Disciplines}

Entertainment, Arts, and Sports Law 


\title{
DEVELOPMENT THROUGH SPORT: FANS AND CRITICS
}

\author{
DANIELLE IRELAND-PIPER*
}

\begin{abstract}
Sport is used as a tool for development, dispute resolution and reconciliation. The use of sport to meet development goals such as education, health and gender equity has grown into a widely recognised form of development assistance, commonly known as 'Development through Sport' (DTS). Further, the right to physical activity is a substantive human right. Nonetheless, the DTS movement has both its fans and critics. This article analyses four common concerns; namely, that DTS is racially constructed, lacking in credibility, poorly coordinated and inadequately evaluated. This article agrees that the DTS movement should improve the delivery and implementation of development goals, but suggests that the criticisms are overstated. They are far outweighed by the benefits of DTS, which meet a number of the United Nations Millennium Development Goals.
\end{abstract}

\section{INTRODUCTION}

Sport is increasingly being used as a tool for development, dispute resolution and reconciliation. The use of sport to meet development goals such as education, health and gender equity has grown into a widely recognised form of development assistance, commonly known as 'Development through Sport' (DTS). DTS is described as 'an area of rapid growth and burgeoning enthusiasm'. ${ }^{1}$ The DTS movement can be defined by its use of 'sport, physical activity and play as tools to facilitate social improvement in nations and communities targeted for development'. ${ }^{2}$ DTS can contribute toward better health outcomes, enhanced self-esteem, social and cognitive development, and academic achievement. ${ }^{3} \mathrm{~A}$ Council of Europe Report ${ }^{4}$ suggests that engagement in sport will help participants develop tolerance and respect for others. ${ }^{5}$ It found there to be 'strong evidence on the positive effects of physical activities on self-concept, self-esteem, anxiety, depression, tension and stress, self-confidence, energy, mood, efficiency and well-being ${ }^{6}{ }^{6}$ Opportunities for sport and physical activity are also substantive human rights, grounded in the Universal Declaration of Human Rights (1948), the International Charter on Physical Education and Sport (1978), the International Convention on the Rights of the Child (1990) and, most recently, the International Convention on the Rights of Persons with Disabilities (2006). However, some commentators argue that DTS is racially constructed, lacking in credibility, poorly

* Senior Teaching Fellow, Bond University, Australia. This paper is a modified version of a presentation at the inaugural Inter-disciplinary Colloquium on Sport Diplomacy, Development and Governance at Bond University, February 2013.

1 David R Black, 'The Ambiguities of Development: Implications for 'Development Through Sport' (2010) 13 Sport in Society 1, 121-9, 122.

2 Simon C Darnell, 'Playing with Race: Right to Play and the Production of Whiteness in Development through Sport' (2007) 10(4) Sport in Society: Cultures, Commerce, Media, Politics, 560-79, 560.

3 See, eg, M Talbot, 'The case for physical education', paper presented at the World Summit on Physical Education, Berlin, Germany (2001), 39-50.

$4 \quad$ Richard Bailey, 'Physical Education and Sport in Schools: A Review of Benefits and Outcomes' 76 (8) Journal of School Health 397, citing B Svoboda, 'Sport and Physical Activity as a Socialisation Environment', Scientific Review Part 1, Council of Europe, 1994.

5 Ibid.

6 Ibid. 
coordinated, and inadequately evaluated. This article acknowledges these concerns, and accepts the DTS movement should seek to improve the delivery and implementation of development goals. In defence of DTS, it is suggested that these criticisms are overstated and the far outweighed by the benefits of DTS, which may assist in realizing a number of the United Nations Millennium Development Goals. ${ }^{7}$

\section{SPORT AS A HUMAN RIGHT}

The right to sport is recognised either expressly or implicitly in the International Charter on Physical Education and Sport (1978) (ICPES), the Universal Declaration of Human Rights (1948) (UNDHR), the International Convention on the Rights of the Child (1990) (CRC) and, most recently, the International Convention on the Rights of Persons with Disabilities (2006) (RPD). Specifically, article 1 of the ICPES asserts the practice of physical education and sport as being a fundamental right for all:

every human being has a fundamental right of access to physical education and sport ... [and the] ... freedom to develop physical, intellectual and moral powers through physical education and sport must be guaranteed both within the educational system and in other aspects of social life. ${ }^{8}$

Article 24 of the UNDHR grants 'the right to rest and leisure' ${ }^{\prime}$, and article 31 of the CRC recognises the right of the child to rest and leisure, to engage in play and recreational activities'. ${ }^{10}$ In a similar vein, article 30(5) of the RPD requires state parties to take appropriate measures to enable 'persons with disabilities to participate on an equal basis with others in recreational, leisure and sporting activities' ${ }^{11}$

\section{DISTINGUISHING SPORT DEVELOPMENT FROM DEVELOPMENT THROUGH SPORT}

This article is concerned with 'Development through Sport' rather than 'Sport Development'. The two are distinguished because the focus and objectives are different. Sport Development describes the efforts made to provide resources for athletes to compete at an elite level, in situations where they otherwise could not access those resources. By contrast, DTS is not focused on the elite athlete. DTS is concerned with achieving social, educational and health objectives at a local level through the medium of sport and related activities. It is the focus on development goals that has opened DTS up to criticisms from the development sector.

See, eg, http://www.un.org/millenniumgoals/.

International Charter of Physical Education and Sport, adopted by the United Nations Educational Scientific and Cultural Organization (UNESCO) General Conference on 21 November $1978<\mathrm{http}$ ://assets.sportand dev.org/downloads/17_intl_charter_of_pe_and_sport.pdf $>$.

9 The Universal Declaration of Human Rights, entered into force 10 December $1948<\mathrm{https} / /$ www.un.org/ en/documents/udhr/index.shtml>.

10 Convention on the Rights of the Child, opened for signature 20 November 1989, (entered into force 2 September 1990) in accordance with article 49.

11 Convention on the Rights of Persons with Disabilities (entered into force 6 December 2006, $<$ http://www.un.org/disabilities/convention/conventionfull.shtml >. 


\section{THE CRITICS}

The development sector is complex. Participants must walk a fine line between cultural relativism and human rights norms. Players must negotiate competing local, national, and international agendas. Given this complexity, it is unsurprising critics have concerns. This article seeks to engage and respond to four of these concerns: the argument by Simon Darnell that delivery of DTS is racially constructed; ${ }^{12}$ the concerns of David Black about the credibility of celebrities in DTS programs; ${ }^{13}$ the suggestion by Bruce Kidd that DTS initiatives are poorly coordinated; ${ }^{14}$ and the difficulties identified by Fred Coalter in evaluating the success of DTS programs. ${ }^{15}$

\section{Concern 1: The Delivery of DTS is Racially Constructed}

DTS is part of a discourse of development. Simon Darnell suggests, '[I]n a dominant discourse of development, the Third World comes to be associated with instability, poverty and exclusion, which serve to characterise Third World nations as definitively underdeveloped'. In his view, the 'First World' response to this instability is understood as benevolent and rational in contrast to an underdeveloped racial 'other'. ${ }^{16}$ In the course of his research, Darnell surveyed volunteers in the DTS sector. He takes issue with what he suggests is racially constructed language in the following quotes:

My mission is to train, to empower, and to help bring a sense of dignity back to these people. ${ }^{\prime 17}$

I was initially concerned about the language barrier. The children all spoke Swahili and we all spoke English (or at least broken English) and French. I quickly learned that in sports, language isn't an issue. A laugh is still a laugh and a smile is still a smile no matter what the language. At the end of our visit we gave them a few soccer balls, Frisbees, volleyballs and a net. I could never imagine American kids being SO excited to receive a few meagre pieces of sporting equipment. You would have thought that we offered them a new pony or something. ${ }^{18}$

Darnell's concern is that the reference to 'these people', and with 'notions of gratitude (being) ... produced as effective means of knowing, and speaking for, the Other ${ }^{\prime 19}$ indicates the delivery and implementation of DTS is racially constructed. He argues:

the construction of a de-politicized, de-historicized 'native' who is seemingly grateful for material means that provide respite from his/her marginalization. The language of gratitude is offered as evidence of the success of volunteer efforts and serves to reconfirm the benevolence of development and the universalism of sport. The White subject position is

Darnell, above $\mathrm{n} 2$.

Black, above $\mathrm{n} 1$.

Bruce Kidd, 'A New Social Movement: Sport for Development and Peace' (2008) 11(4) Sport in Society: Cultures, Commerce, Media, Politics 370-380.

15 Fred Coalter, 'The Politics of Sport for Development: Limited Focus Programmes and Broad Gauge Problems?' (2010) 45(3) International Review of the Sociology of Sport 295-315.

Darnell, above n 2, 564 .

Right to Play, 2002 Annual Report cited in: Darnell, above n 2, 560.

Ibid 570 .

Ibid. 
constructed ... as generous and benevolent and in opposition to racial Others, recognized as ... grateful. ${ }^{20}$

Some providers of DTS have made errors of judgment and not all motives are pure. However, to taint all expressions of delight at another's gratitude as being racially constructed is to ignore that people may exhibit gratitude for aid simply because they are poor, and not because they are a racial 'other'. The need for the joy derived from play, and gratitude for the opportunity to satisfy that need, is universal. This is reflected by the inclusion of the right to physical activity and play in international human rights frameworks. ${ }^{21}$ No doubt, an impoverished 'white' child would be equally excited by the provision of sporting equipment or the opportunity to play. As Roger Levermore and Aaron Beacom suggest, the very basis of the Darnell's criticism is over-generalized, and 'not rooted in field experience'. ${ }^{22}$ They argue that it ignores the DTS projects that take place at a grass roots level, and 'in local environments with little (or less than presumed) influence from international, Northern institutions, networks and political, economic and cultural pressures'. ${ }^{23}$ Ultimately, any provider of aid should ensure that there is a culture of equality and good faith. The opinions, ownership, and participation of local communities are essential. True partnerships are built on mutual respect, and are an inherent requirement of successful development delivery.

\section{Concern 2: Credibility}

Many organisations in the development sector use celebrity endorsement or ambassadorship. For example, footballer David Bekham became an ambassador for the Sport for Development program run by charity organisation, UNICEF. ${ }^{24}$ Similarly, Leo Messi gave his support to UNICEF's 'End Child Deaths' campaign. ${ }^{25}$ The organisation Right to Play also makes use of celebrity endorsement and ambassadorship, including such names as ice-hockey star Wayne Gretzky, swimmer Ian Thorpe, and Frank Lampard, a famous Chelsea and England footballer. ${ }^{26}$ It is easy to see the attraction of celebrity endorsement, particularly in terms of raising awareness and financial support. However, David Black argues there is a need to emphasise the 'resilience and creativity of local communities, rather than the benevolence and celebrity of these sport heroes' ${ }^{27}$ In his view, the 'use of celebrity needs to be carefully undertaken.' ${ }^{28}$ Further, George Cunningham and Michael Reagan observe that sport celebrities are often engaged in lucrative sponsorship arrangements. This may hamper, or be seen to hamper, their ability to speak freely. ${ }^{29}$ For example, when

20 Darnell, above n 2, 570.

21 See, eg, Universal Declaration of Human Rights (1948), the International Charter on Physical Education and Sport (1978), the International Convention on the Rights of the Child (1990) and, most recently, the International Convention on the Rights of Persons with Disabilities (2006).

22 Roger Levermore and Aaron Beacom, 'Reassessing Sport-for-Development: Moving Beyond 'Mapping the Territory" (2012) 4 International Journal of Sport Policy and Politics 1, 125-137, 127.

23 Ibid.

24 For example, see <http://www.unicef.org.uk/UNICEFs-Work/Our-supporters/Celebrities/David-Beckham/>.

25 For example, see <http://southasia.oneworld.net/newsmakers/lionel-messi-end-child-deaths $>$.

26 Right to Play, Website, < http://www.righttoplay.com/International/the-team/Pages/OurAthletes.aspx >.

27 Black, above n 1, 126.

28 Ibid.

29 George B Cunningham and Michael R Regan, Jr, 'Political Activism, Racial Identity and the Commercial Endorsement of Athletes' (2012) 47 International Review for the Sociology of Sport 657, 658. 
Michael Jordan was asked why he did not endorse an African American democrat candidate, he reportedly responded 'Republicans buy sneakers, too'. ${ }^{30}$ Cunningham and Reagan continue:

Speaking out on controversial issues, such as the wars in Iraq and Afghanistan, racism or poverty might negatively impact the degree to which these attributions are made to the athlete. On the other hand, other forms of activism, such as engaging in efforts to reduce obesity or providing aid following natural disasters, are likely to be viewed positively, and as such, notions of dependability, honesty, and sincerity will likely increase. ${ }^{31}$

Nonetheless, the use of celebrity can be a powerful tool in raising awareness. In so doing, the DTS movement should ensure that there are local heroes too, and a good deal of transparency and accountability in the choice of celebrity endorsement.

\section{Concern 3: Coordination}

In 2008, Bruce Kidd described DTS as 'still in its infancy, woefully underfunded, completely unregulated, poorly planned and coordinated and largely isolated from mainstream development efforts. ${ }^{32}$ Poor coordination is an ongoing issue in the development sector. For example, a lack of coordination in the delivery of aid has been described as 'leading to redundancy, policy incoherence, inefficient use of resources, and unnecessary administrative burdens on host countries. ${ }^{33}$ Commentators suggest that DTS programs are so poorly coordinated that organisations not only duplicate initiatives, but compete with each other for funding. Kidd refers to situations in which DTS non-governmental organisation's competed with local public schools for funding. ${ }^{34}$ Coalter also observes the problem of competition for limited resources. He suggests this 'frequently leads to projects being developed to fit the funding criteria, with the potential to compromise' ${ }^{35}$ needs and cause 'mission drift'. ${ }^{36}$ However, increased coordination can present challenges where strategic policy objectives or accountability standards vary $\cdot^{37}$ Further, as a 2013 report by the Congressional Research Service observes,

The growing role of non-traditional donors, as well as private sector investments and philanthropic financial flows to developing countries, present additional coordination challenges....38

In any event, more effective regulation of the DTS sector and improved management practices are desirable. The establishment of an international regulatory body to develop models of best practice, accountability mechanisms and to better coordinate initiatives may be useful.

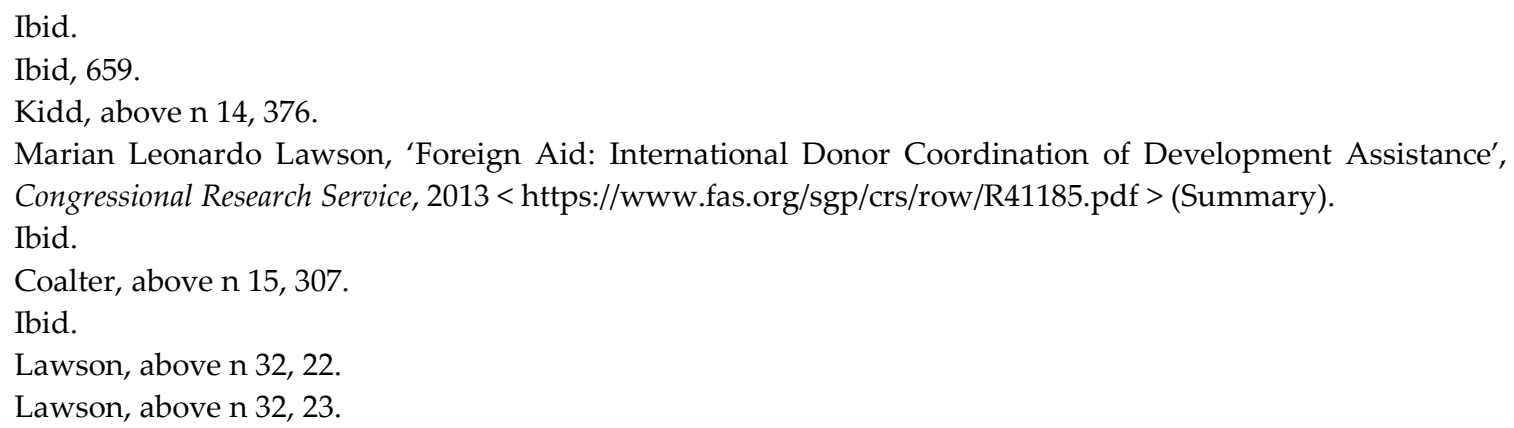




\section{Concern 4: Evaluation processes}

Fred Coalter contends that evaluation mechanisms should be considered an integral part of DTS programmes. He refers to the 'almost evangelical policy rhetoric of ... sports-fordevelopment' ${ }^{39}$, operating under a 'vague and weakly theorised banner'. ${ }^{40}$ DTS, like any community sector, must balance the demand for quantifiable outcomes, with the reality that long term socio-economic benefits are extraordinarily hard to quantify. For example, it is difficult to measure how many crimes were prevented by engaging young people in sport, to quantify the increased self-esteem of a child who negotiates his way in a team, or evaluate the opportunity provided to a girl who is taught how to best prevent the spread of HIV. As Kruse observes, 'we have not come across any systematic analysis of how to understand the relationships between sport and development ... the positive beliefs seem to be based on an intuitive certainty and experience that there is a positive link...'. ${ }^{41}$ Levermore and Beacom agree that it is not easy to quantify the achievement of a "range of social and community goals, including the notion that it can "bring together" young people.' ${ }^{42}$

Nevertheless, evaluation mechanisms play an important part in ensuring funds are efficiently allocated and in creating a level of accountability to relevant stakeholders. Better evaluation processes may take time, but they are ultimately a 'win-win'. There is reduced opportunity for corruption, and misappropriation, as well as an increased opportunity for efficiency, and accountability. Better evaluation processes would provide an opportunity for DTS programs to generate awareness of the effectiveness of sport in tackling development goals. For example, the Swedish International Development Cooperation Agency and the Danish Ministry of Foreign Affairs engaged in a six-year evaluation period. As a result the Cross Cultures Project Association, which runs Open Fun Football Schools program, was recognised for establishing 'an effective network of coaches and leaders across its countries of operation and the bonds and friendships ... [which has] ... served to break down enemy images and promote reconciliation'. ${ }^{43}$

\section{Preliminary conclusions on the four concerns}

These four concerns identify important issues and ways in which the DTS sector can improve the delivery and implementation of programs and initiatives. Racial constructs should be avoided and local communities must be given a meaningful role in DTS programs. The use of celebrity should be undertaken carefully, programs should be better coordinated and regulated, and evaluation mechanisms must be in place. In defence of DTS, it is suggested that these criticisms are overstated and the far outweighed by the benefits of DTS.

\section{IN DEFENCE OF DEVELOPMENT THROUGH SPORT}

The wider community benefits of sport date back to ancient times. Heather Reid observes, 'Olympic sport taught the ancient Hellenes something about peace by obliging them to set

Coalter, above n 15, 295.

Ibid.

SE Kruse, 'Review of Kicking AIDS Out: Is Sport an Effective Tool in the Fight Against HIV/AIDS? Draft report to NORAD, unpublished. cited in Coalter, above n 15, 309.

42 Levermore and Beacom, above n 22, 132.

43 Cross Cultures Projects Association, External Evaluation Study <http://www.ccpa.eu/1-588-evaluations-andacademic-reports-.html> 
aside their conflicts, treat others as equals, and tolerate differences' ${ }^{\prime 4}$ Today, sport offers 'alternative conduits for addressing health, education and other developmental concerns...'. ${ }^{45}$ Sport and play has many positive qualities, and can be used to educate, bridge social divides, complement conflict resolution, and promote healthy living, gender equality and the inclusion of persons with disabilities. To illustrate some of these benefits, five examples of DTS programs are considered in context of a number of the United Nations Millennium Development Goals.

\section{The United Nations Millennium Development Goals}

The Millennium Development Goals (MDGs) are eight development goals established following the adoption of the United Nations Millennium Declaration (the Millennium Declaration) by 190 member states. ${ }^{46}$ The goals are:

1. Eradicating extreme poverty and hunger;

2. Achieving universal primary education;

3. Promoting gender equality and empowering women;

4. Reducing child mortality rates;

5. Improving maternal health;

6. Combating HIV/AIDS, malaria, and other diseases;

7. Ensuring environmental sustainability; and

8. Developing a global partnership for development.

To illustrate how DTS may assist in further realising these MDGs, five examples of DTS programs are set out below.

Example 1: GOALS (relevant MDGs may include: promoting gender equality and empowering women; ensuring environmental sustainability; and developing a global partnership for development).

'GOALS' is an NGO located in Haiti. Haiti experienced a destructive earthquake in January 2010. ${ }^{47}$ GOALS emphasises the importance of the environment and engages local youth through the integration of sport into after-school activities, summer camps, community outreach programs, competitive leagues and high school scholarships. ${ }^{48}$ Each team of Haitian children and a local leader must participate in eight hours of soccer practice/competition, two hours of community service and two hours of education. ${ }^{49}$ In its annual report, GOALS emphasises the need to reverse aid dependency in the DTS sector. It seeks to identify projects that matter most to the local community. ${ }^{50}$ The rationale behind this is avoiding 'aid fatigue', where operations cease to exist if aid donors withdraw. As a result, GOALS is reportedly comprised of an almost entirely local and Haitian leadership

$44 \quad$ Heather Reid, 'Olympic Sport and Its Lessons for Peace' (2006) 33 Journal of the Philosophy of Sport 205.

$45 \quad$ Levermore and Beacom, above n 22, 137.

46 United Nations Millennium Declaration, unanimously adopted by the General Assembly (A/54/L.89), final day of its 54th Session, September 5, 2000.

47 See, eg, the Oxfam Website, < http://www.oxfam.org/en/haitiquake >.

48 GOALS, < http://goalshaiti.org/model-and-values/ >.

49 GOALS, Annual Report, (2012), 6, <http://goalshaiti.org/wp-content/uploads//2012/07/GOALS-2012-AnnualReport1.pdf $>$.

50 Ibid. 
team. According to its annual report, GOALS provides programs for 636 children per-month and granted 23 scholarships to high school students last year. ${ }^{51}$ Half of the official teams are 'girls only', tackling issues of gender equity. This is significant because the promotion of gender equity and the empowerment of women is one of eight MDGs.

Example 2: Right to Play (relevant MDGs may include: reducing child mortality rates; achieving universal primary education; and developing a global partnership for development).

The international non-government organisation (NGO), Right to Play sends teams of volunteer coaches and development professionals into over twenty countries, reaching thousands of children per week. ${ }^{52}$ It does so with the stated view of enhancing healthy child and community development. ${ }^{53}$ The organisation was started by an Olympic speed skater, Johann Koss, and was originally known as 'Olympic Aid'. ${ }^{54}$ Koss has been described not only as 'a visionary, but a gifted strategic leader and diplomat, forging links well beyond the comfortable family of international and national sports organizations' ${ }^{55}$ Operations began in Canada in 2000 and have now expanded to five additional international offices across the globe in Norway, the Netherlands, Switzerland, the United Kingdom and the United States. ${ }^{56}$ By the end of 2001, Right to Play had 37,000 children participating in its programs. ${ }^{57}$ In 2009 , this number increased to 1.17 million children. ${ }^{58}$ At the end of 2009, Right to Play had 49 worldwide projects, and had trained 13,000 local leaders.59

Example 3: Open Fun Football Schools (relevant MDGs may include: reducing child mortality rates; and developing a global partnership for development).

The Open Fun Football Schools (OFFS) uses sport to promote the process of democracy, peace, stability and social cohesion. It generally operates in Balkan, Transcaucasus, and Middle Eastern nations. ${ }^{60}$ This program focuses its platform on rebuilding war-torn societies by socialising children and their communities through football, or soccer, as it is more commonly known in some parts of the world, including Australia. It seeks to design educational components that will assist in breaking down prejudice and mistrust. Both the children and instructors come from different ethnic backgrounds. The organisation utilises the 'twin-city strategy' which ties together different football clubs, leaders and teachers from at least two apparently hostile regions who play together. ${ }^{61}$

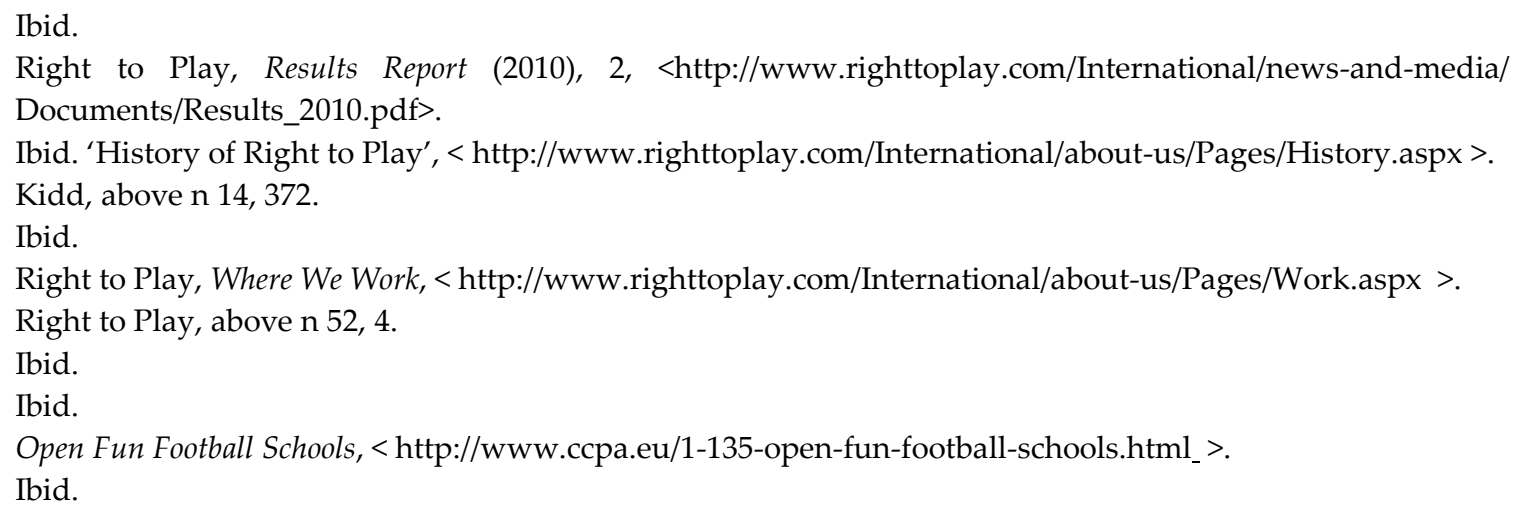


Example 4: Girls Kick It! (Relevant MDGs may include: eradicating extreme poverty and hunger; promoting gender equality and empowering women; and combating HIV/AIDS, malaria, and other diseases ).

The Girls Kick It! project is a soccer program that empowers young women in the postconflict areas in northern Uganda by combining sport with education, practical business training and personal development. ${ }^{62}$ It uses a 'peer-to-peer' training model, where girls teach each other about important topics such as HIV/AIDS prevention, nutrition, domestic violence and personal hygiene. ${ }^{63}$ It also introduced the 'Gweno (chicken) Cooperative Enterprise Project', to provide participants with the opportunity to learn and develop business and management skills. ${ }^{64}$ The initiative offers each soccer team the challenge of managing and maintaining a poultry house together as a group. Each unit is responsible for the sale of the chickens, management of funds and organization of the business operations. ${ }^{65}$ The profits from the sale of the chickens to the local community are put towards school fees, sport expenses and the development of new businesses. ${ }^{66}$ The goal of the project is to provide practical business experience, build confidence in the workplace and shape community leaders. ${ }^{67}$ In 2012, Girls Kick It was awarded the 'Sport for Social Inclusion Award' by international organisation Beyond Sport. ${ }^{68}$ Beyond Sport is a high profile organisation, with support from high profile persons such as Archbishop Desmond Tutu. ${ }^{69}$

\section{Example 5: Kicking Aids Out (relevant MDG may include: combating HIV/AIDS, malaria, and other diseases).}

In East Africa, the Kicking Aids Out network uses sport to teach personal health and sexual responsibility to vulnerable youth. ${ }^{70}$ This is significant considering that more than half of persons newly infected by HIV in East Africa are between 15 and 24 years of age, and most of those will die before their $35^{\text {th }}$ birthday. ${ }^{71}$

Example 6: Mifalot (this final example is not necessarily linked to one of the eight MDGs, but it does illustrate the potential of DTS for conflict resolution).

Mifalot is an organization under the auspices of a professional soccer club in Israel. ${ }^{72}$ Mifalot delivers programs across the Israeli, Palestinian and Jordanian borders, reaching over 20,000 children and youth. ${ }^{73}$ Mifalot engages participants in soccer, to build stronger community

\footnotetext{
62 Girls Kick It!, Website, < http://www.girlskickit.org/?page_id=503 >.

63 Ibid.

$64 \quad$ Ibid.

65 Ibid.

$66 \quad$ Ibid.

$67 \quad$ Ibid.

68 Beyond Sport, Beyond Sport Awards 2012, <http://www.beyondsport.org/the-awards/awards2012/ entries/winners.php>.

69 Archbishop Desmond Tutu is an official patron of 'Beyond Sport'. See: <http://www.beyondsport. org/behind-beyond/people/view/67 >.

70 Kicking Aids Out, < http://www.kickingaidsout.net $>$.

71 Kidd, above n 14, 370.

72 Mifalot, < http://www.mifalot.co.il/mifalot/Language/English/info.aspx?id=69 >. The author is grateful to Cory Sterling for alerting her to the existence of this organisation.

73 Ibid.
} 
ties and destroy racial prejudices in the Middle East. ${ }^{74}$ The organization seeks to educate its participants and provides social tools to build confidence and self-esteem, and eliminate prejudice. ${ }^{75}$ Mifalot has also worked with communities in Rwanda and Cameroon using sport as a tool to provide exercise, education and bridge social divides. ${ }^{76}$

These six examples illustrate that DTS is being used to assist in improving community relations, sexual health, nutrition, financial literacy, and gender equity. These are significant benefits, and bear a strong relationship with a number of the eight MDGs. The Millennium Declaration itself urges member states 'to observe the Olympic Truce, individually and collectively, now and in the future, and to support the International Olympic Committee in its efforts to promote peace and human understanding through sport and the Olympic Ideal' ${ }^{77}$ More recently, the UN General Assembly passed a resolution, not the first of its kind, on sport entitled, Sport as a means to promote education, health, development and peace. ${ }^{78}$ The resolution encourages the use of sport as a vehicle to foster development and strengthen education. It also aims to prevent disease, empower girls and women, promote the inclusion and wellbeing of persons with disabilities, and facilitate conflict prevention and peace-building. In 2002, Kofi Annan, the then United Nations Secretary General, reflected:

Sport can play a role in improving the lives of individuals; not only individuals, I might add, but whole communities. I am convinced that the time is right to build on that understanding, to encourage governments, development agencies and communities to think how sport can be included in the midst of poverty, disease and conflict. ${ }^{79}$

\section{CONCLUSION}

Critics of DTS raise valid concerns and, no doubt, there is room for improvement in the DTS sector. The needs of the community must be prioritised above the desires of the donor. Participants should be appropriately briefed, and adequate regulatory and accountability mechanisms put in place. DTS initiatives could be better coordinated and more efficient. Especially when conducted in responsible and culturally appropriate ways, DTS initiatives have 'enhanced the education, health and well-being of participants'. ${ }^{80}$ As such, DTS programmes can assist in achieving a number of the MDGs, and in realising the right to sport and play.

American sports commentator, Howard Cosell, concluded that 'sport is human life in microcosm'. Much of what makes us hurt as humans can be worked through on the sporting field. In sport, we negotiate, we demand, we cede. We fall, we get back up again. We vent, we learn, we play. We sweat, we bleed, and are victorious. We throw our weapons

\footnotetext{
$74 \quad$ Ibid.

$75 \quad$ Ibid.

76 Street Football World, Mifalot on CNN, [video], <http://www.streetfootballworld.org/network/allnwm/Mifalot/blog/mifalot-on-cnn>.

77 The Millennium Declaration, above $\mathrm{n} 46$.

78 'Sport as a means to promote education, health, development and peace', A/RES/67/17, 28 November $2012<$ http://www.un.org/wcm/content/site/sport/home/resourcecenter/resolutions/pid/19431 >.

79 Coalter, above n 15, 302.

80 Kidd, above n 14, 376.
} 
at a common adversary, and then grasp hands with them afterwards. We make mistakes, and are sorry. There are tears, and there is elation. There are rules, and there is closure. As Irish Essayist Robert S Lynd once observed, 'it may be that all games are silly. But then, so are humans'. 